\title{
(C) OPEN ACCESS \\ Into the black: Marlboro brand architecture, packaging and marketing communication of relative harm
}

\author{
Timothy Dewhirst
}

Department of Marketing and Consumer Studies, University of Guelph, Guelph, Canada

Correspondence to Professor Timothy Dewhirst, Department of Marketing and Consumer Studies, College of Business and Economics, University of Guelph, Guelph, Ontario N1G 2W1, Canada; dewhirst@uoguelph.ca

Published Online First 21 April 2017
Check for updates

To cite: Dewhirst T.

Tob Control

2018:27:240-242.
In 2008, Philip Morris International (PMI) launched a new global brand architecture for Marlboro, which involved establishing three Marlboro brand families known as Red (centred on flavour), Gold (based on contemporary style with contrasting diameters and taste profiles) and Fresh (being mentholated and dubbed as 'refreshing taste sensations'). The new brand architecture includes Marlboro brand variants being offered in black-coloured cigarette packages. For example, as part of the Marlboro Fresh product line, Marlboro Black Menthol was launched in Japan during 2008, and soon thereafter offered in several additional markets, including Indonesia and the Philippines. ${ }^{1}$ According to PMI's 2008 annual report, Marlboro Black Menthol was launched 'to deliver a cigarette with a bold, longlasting, high-cooling sensation in a striking black pack. The brand's boldness is represented by a strong black stallion in motion, the main element of the communication campaign' (figure 1). ${ }^{2}$ Additional Marlboro offerings from the Fresh pillar include Ice Blast and W-Burst (also launched in Japan), Blue Ice (launched in Brazil), as well as Kretek Mint and Black Freeze (launched in Mexico, where the company possesses over $80 \%$ of the menthol segment). By 2011, PMI had developed over 220 new or redesigned brand variants for Marlboro, with Marlboro Fresh variants available in more than 90 markets. ${ }^{13-5}$

The use of brand extensions or variants has facilitated tobacco companies such as PMI to ably position and create the perception that some cigarettes are healthier versions of others. According to PMI's website, the primary role of brand variants is to 'offer products with differing yields of tar and nicotine, as measured by standardized test methods. Where permitted, we use terms such as 'low-tar,' 'light,' 'ultra-light,' 'medium' and 'mild' to facilitate consumers' ability to distinguish among these different product offerings. ${ }^{6}$ Where not permitted to use such product descriptors, a colour-coding system has been used to ensure that variants remain associated with descriptors (eg, 'Light', 'mild', 'low tar') previously deemed misleading and deceptive, and distinctions can still be made among variants on the basis of their sequential tar yields. ${ }^{7-9}$ For the Marlboro brand family historically, red has signified the parent brand and is commonly used for regular cigarettes, whereas blue, gold and silver are commonly understood to signal sequentially 'lighter' variants. ${ }^{10}$
Black was likely selected by PMI as a package colour for Marlboro to communicate the brand's premium or market leadership status. Black packaging is associated with higher priced products, prestige and elegance. ${ }^{11}$ Black is commonly used by those in creative design to convey sophistication (eg, tuxedos and black clothing as a fashion statement), importance and respect (eg, limousines and official cars that transport dignitaries are commonly black) and appearing authoritative. ${ }^{12} 13$ Specific to cigarette packaging, internal documentation from Philip Morris indicates that shiny or textured black backgrounds communicate 'classy, contemporary, distinguished, stylish, rich, aspirational (important, competent, successful)' attributes to consumers. ${ }^{14}$ Although the meaning of colours can vary cross-culturally, 'expensive', 'powerful' and 'authority' are meanings associated with black that transcend domestic markets, including several Asian cultures such as China, Japan and South Korea. ${ }^{15}$

Intrafamily codes continue to be used to infer relative harm for PMI's new brand architecture that includes Marlboro brand variants being offered in black-coloured cigarette packages. A hierarchy of relative harm is communicated on the basis of

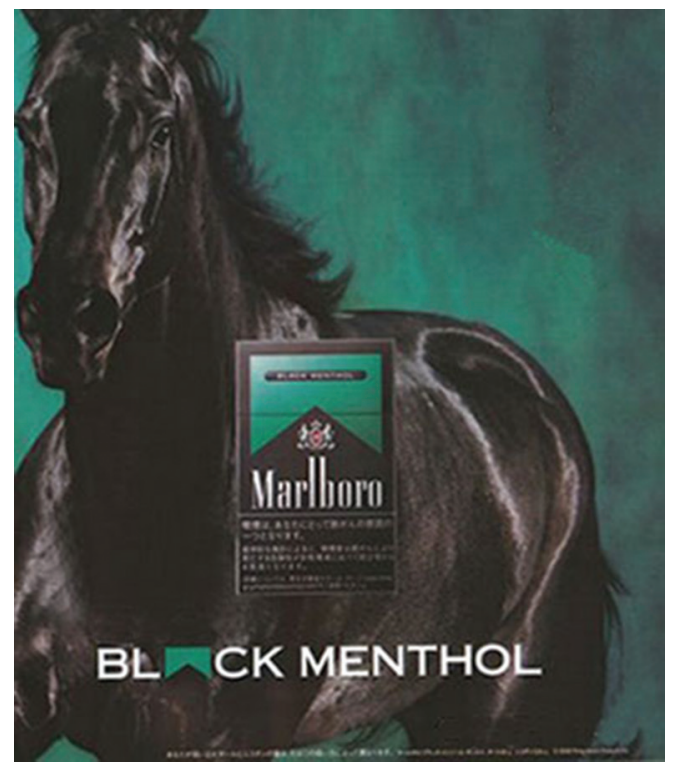

Figure 1 When Marlboro Black Menthol was launched in Japan, marketing communication for the brand depicted a strong black stallion in motion. The brand's marketing communication in Indonesia and the Philippines also featured a black stallion. 


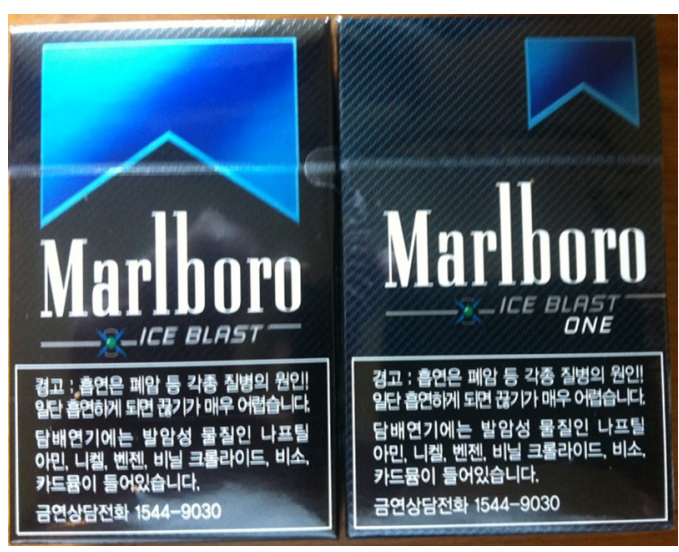

Figure 2 Cigarette packages for Marlboro Ice Blast variants in South Korea, where a larger blue-coloured rooftop is seen for the variant with a supposed tar yield of $6.0 \mathrm{mg}$ and a comparatively smaller-sized rooftop is used for the variant reporting a tar yield of $1.0 \mathrm{mg}$. The size of the Marlboro rooftop serves as a code for communicating the relative machine-measured tar yield.

numbers and size of the Marlboro rooftop symbol. As seen in figure 2, Marlboro Ice Blast offerings both portray blue-coloured rooftops, but a larger rooftop is observed for the variant with a supposed tar yield of $6.0 \mathrm{mg}$, whereas a comparatively smaller-sized rooftop is used for the variant with a supposed tar yield of $1.0 \mathrm{mg}$. Moreover, to reinforce the importance of $1.0 \mathrm{mg}$ being a low nominal tar yield, the smaller rooftop variant is identified as Marlboro Ice Blast One. When purchasing both variants of Marlboro Ice Blast at a convenience store in South Korea, the receipt pointed to the brand variants' comparative machine-measured tar yields alongside the price (figure 3). As seen in figure 4, advertising at the point of sale explicitly

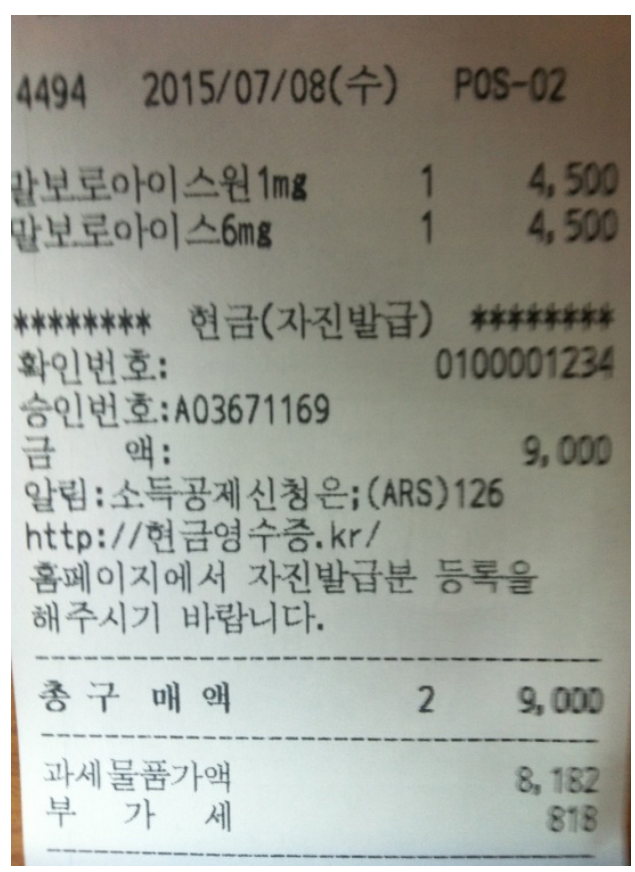

Figure 3 When the cigarette packages for Marlboro Ice Blast variants were purchased in South Korea from a convenience store during 2015, the receipt pointed to the price (ie, 4500 Korean Won (KRW), which is equivalent to nearly US\$4) as well as the brand variants' comparative machine-measured tar yields (6 mg and $1 \mathrm{mg}$ ). identifies the comparative reported tar deliveries of the variants and highlights the different sized blue-coloured rooftops as a code for the corresponding reported tar delivery. In Japan, Marlboro Ice Blast variants are offered from a vending machine with reported tar yields of $8 \mathrm{mg}, 5 \mathrm{mg}$ and $1 \mathrm{mg}$ and the cigarette packaging depicts numbers and sequentially different rooftop sizes to communicate comparative tar yields (figure 5).

The offering of variants and line extensions prompt the perception that there is a hierarchy of 'strength', based on sequentially reported tar yields, and thereby an apparent offering of sequentially 'less harmful' options from the parent anchoring brand. Advertising and promotions that point to a cigarette brand's supposed low-tar delivery are regarded as misleading, however, as tar and nicotine yields generated for cigarettes smoked by machines are appreciably lower than the yields actually delivered to compensating smokers. ${ }^{16-22}$ Policy interventions to counteract tobacco companies from communicating a hierarchy of supposed relative harm within brand families include implementation of: (1) standardised packaging with one standard package colour and no imagery and design elements allowable (as observed in Australia) and (2) a single presentation requirement, which means that tobacco companies can offer only one member of a brand family (as observed in Uruguay). Thus, PMI, for example, can offer Marlboro Red or Marlboro Gold, but not both in Uruguay (the company can only offer one 'Marlboro'). It remains the option of tobacco companies as to which brand variant they want to offer, but

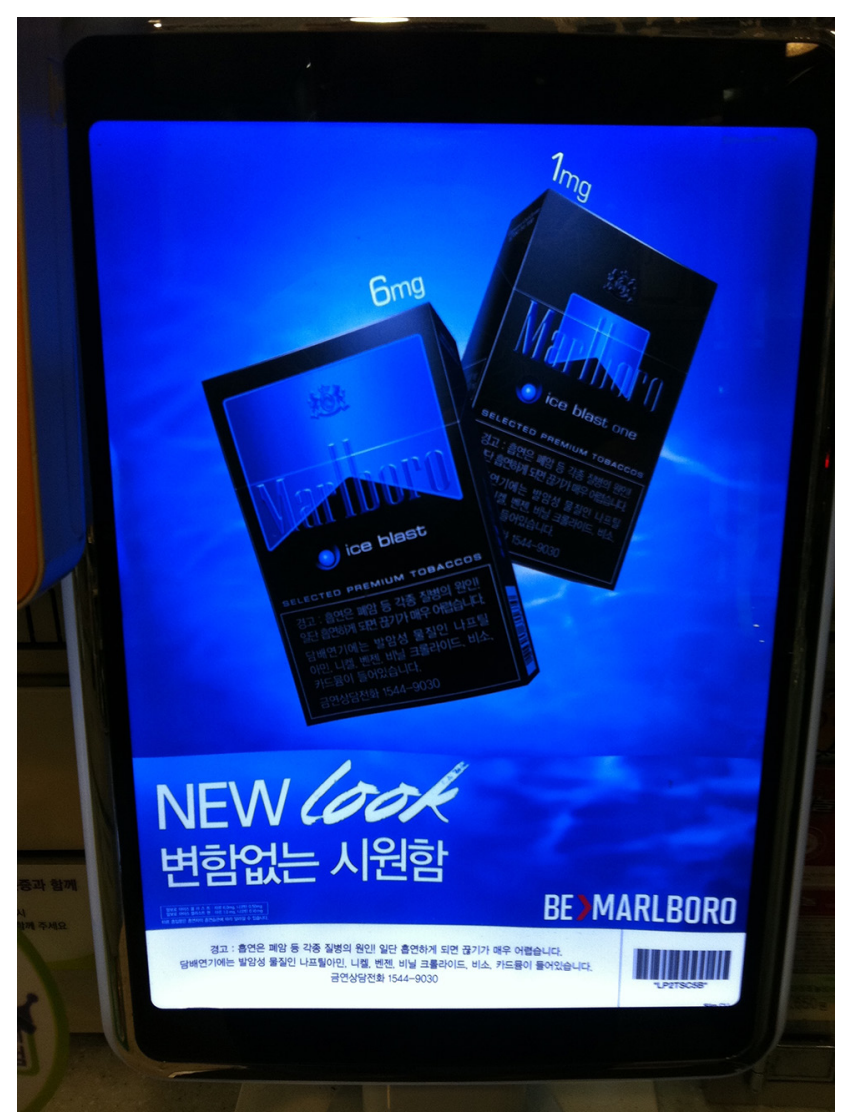

Figure 4 Point-of-sale advertising for Marlboro Ice Blast at a convenience store in South Korea, where ad copy refers to the brand's 'new look' (in English), which presumably refers to the cigarette packaging, while indicating that the coolness, as experienced from the flavour capsule, remains unchanged (in Korean). The photo, dated 18 July 2015, was taken by Timothy Dewhirst. 


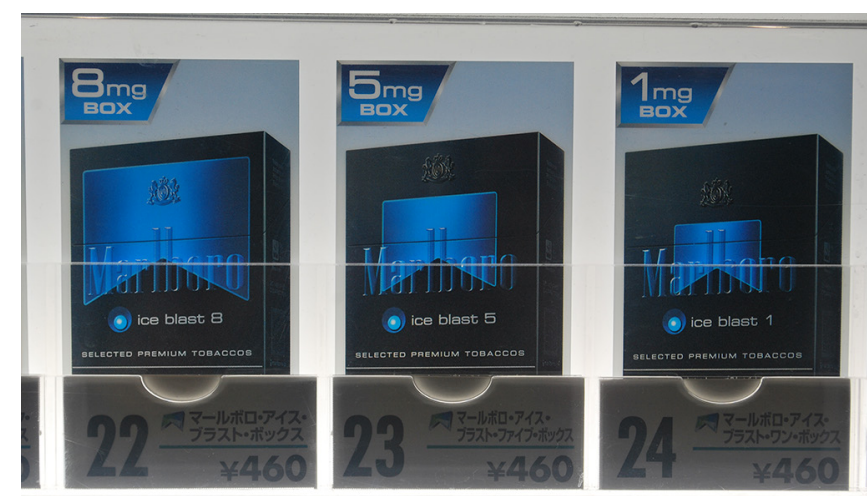

Figure 5 Marlboro Ice Blast variants available from a vending machine in Japan with reported tar yields of $8 \mathrm{mg}, 5 \mathrm{mg}$ and $1 \mathrm{mg}$ and the cigarette packaging depicts numbers and sequentially different rooftop sizes to communicate comparative tar yields. The price is listed as 460 Japanese Yen, which is equivalent to slightly more than US\$4. The photo, dated 1 November 2016, was taken by Timothy Dewhirst.

they are not allowed to offer multiple variants of a brand family, given that cigarette brand families are typically based on a hierarchy of reported tar yields with variants subsequently inferring a hierarchy of reduced harm.

Contributors TD was the sole contributor to the writing and analysis of the study.

Funding This work was supported by an award from the Institute for Global Tobacco Control at the Johns Hopkins Bloomberg School of Public Health with funding from the Bloomberg Initiative to Reduce Tobacco Use.

Competing interests TD is an associate editor of Tobacco Contro/ with respect to product marketing and promotion. He has served as an expert witness in tobacco litigation, including for governments, in countries whose policies are being challenged by parties under trade agreements.

Provenance and peer review Not commissioned; externally peer reviewed.

Open Access This is an Open Access article distributed in accordance with the Creative Commons Attribution Non Commercial (CC BY-NC 4.0) license, which permits others to distribute, remix, adapt, build upon this work non-commercially, and license their derivative works on different terms, provided the original work is properly cited and the use is non-commercial. See: http://creativecommons.org/ licenses/by-nc/4.0/

(C) Article author(s) (or their employer(s) unless otherwise stated in the text of the article) 2018. All rights reserved. No commercial use is permitted unless otherwise expressly granted.

\section{REFERENCES}

1 Philip Morris International. 2009 Annual report. 2009 https://www.pmi.com/investorrelations/reports-filings.

2 Philip Morris International. 2008 Annual report. 2008:13 https://www.pmi.com/ investor-relations/reports-filings.

3 Philip Morris International. 2010 Annual report. 2010 https://www.pmi.com/investorrelations/reports-filings.

4 Philip Morris International. 2011 Annual report. 2011 https://www.pmi.com/investorrelations/reports-filings.

5 Philip Morris International. 2013 Annual report. 2013 https://www.pmi.com/investorrelations/reports-filings.

6 Philip Morris International. Regulation of descriptors. Available at: http://www.pmi. com/eng/tobacco_regulation/regulating_tobacco/pages/regulation_of_descriptors. aspx.

7 Anderson SJ, Ling PM, Glantz SA. Implications of the federal court order banning the terms 'light' and 'mild': what difference could it make? Tob Control 2007;16:275-9.

8 Bansal-Travers M, O'Connor R, Fix BV, et al. What do cigarette pack colors communicate to smokers in the US? Am J Prev Med 2011;40:683-9.

9 Connolly GN, Alpert HR. Has the tobacco industry evaded the FDA's ban on 'Light' cigarette descriptors? Tob Control 2014;23:140-5.

10 Wilson D. Coded to obey law, lights become Marlboro gold. NY Times 2010.

11 Ampuero O, Vila N. Consumer perceptions of product packaging. J Cons Mark 2006;23:100-12.

12 Edwards B. Color: a course in mastering the art of mixing colors. New York: Jeremy P. Tarcher/Penguin Books, 2004.

13 Sutton T, Whelan BM. The complete color harmony. Gloucester, MA: Rockport Publishers, 2004.

14 Lopez A. Summary of consumer learning about packaging elements. Philip Morris USA documentation [inter-office correspondence]; 1992 (November 18): Bates No. 2049 067763. https://www.industrydocumentslibrary.ucsf.edu/tobacco/docs/\#id= jrfc0117

15 Aslam MM. Are you selling the right colour? A cross-cultural review of colour as a marketing cue. J Mark Comm 2006;12:15-30.

16 National Cancer Institute. Risks associated with smoking cigarettes with low machinemeasured yields of tar and nicotine. Smoking and tobacco control monograph No. 13. Bethesda, MD: US Department of Health and Human Services, National Institutes of Health, National Cancer Institute, 2001.

17 Canova D, Myers ML, Smith DE, et al. Changing the future of tobacco marketing by understanding the mistakes of the past: lessons from 'lights'. Tob Control 2001;10:43-4.

18 Kozlowski LT, O'Connor RJ. Cigarette filter ventilation is a defective design because of misleading taste, bigger puffs, and blocked vents. Tob Control 2002;11:40-50.

19 Benowitz NL, Jacob P, Bernert JT, et al. Carcinogen exposure during short-term switching from regular to 'light' cigarettes. Cancer Epidemiol Biomarkers Prev 2005;14:1376-83.

20 Wakefield M, Morley C, Horan JK, et al. The cigarette pack as image: new evidence from tobacco industry documents. Tob Control 2002;11:73-80.

21 Pollay RW, Dewhirst T. The dark side of marketing seemingly 'Light' cigarettes: successful images and failed fact. Tob Control 2002;11:18-31.

22 Hoek J, Dewhirst T. The meaning of 'Light' and 'Ultralight' cigarettes: a commentary on Smith, Stutts, and Zank. J Public Policy Mark 2012;31:223-31. 